\title{
Using Bayesian networks to advise NRM agencies how to influence the adoption of water use efficiency practices by groundwater license holders
}

\author{
$\underline{\text { Jenifer Ticehurst }}{ }^{\text {a,c }}$ and Allan Curtis ${ }^{\text {b,c }}$ \\ ${ }^{a}$ Integrated Catchment and Management Centre, Fenner School of Environment and Society, ${ }^{b}$ Institute for \\ Land, Water and Society, Charles Sturt University, ${ }^{c}$ National Centre for Groundwater Research and \\ Training \\ Email: Jenifer.Ticehurst@anu.edu.au
}

\begin{abstract}
Many new agricultural practices need to be modified if they are going to be sustainable into the future, and this requires adoption by rural landholders. Adoption is a complex process and is typically different for different practices, landholders and contexts. However, it is possible to identify factors that are influential and amenable to influence by natural resource management agencies, and those that are less amenable, but which need to be considered for effective engagement. In this paper we develop a Bayesian network model to explore the influences on the adoption of a set of water efficient management practices, in response to climate change and water entitlement policy, in the Namoi Catchment, an irrigation region of New South Wales, Australia (Figure 1). The management practices included are spray irrigation, soil moisture mapping and modification of flood irrigation methods, measuring dam evaporation and deepening
\end{abstract} dams, buying water on the temporary or permanent water markets, and changing the crop type and rotation frequencies. A survey of groundwater license holders gathered the data that form the basis of the model (Sharp and Curtis, 2012). Through statistical analysis, those researchers identified a set of variables (from values and beliefs, to property characteristics) that are correlated to the uptake of these practices. The Bayesian network is used to explore the causal relationships between these, and then prioritise which factors have the most influence over adoption.

Of the management practices included, groundwater license holders' were most likely to

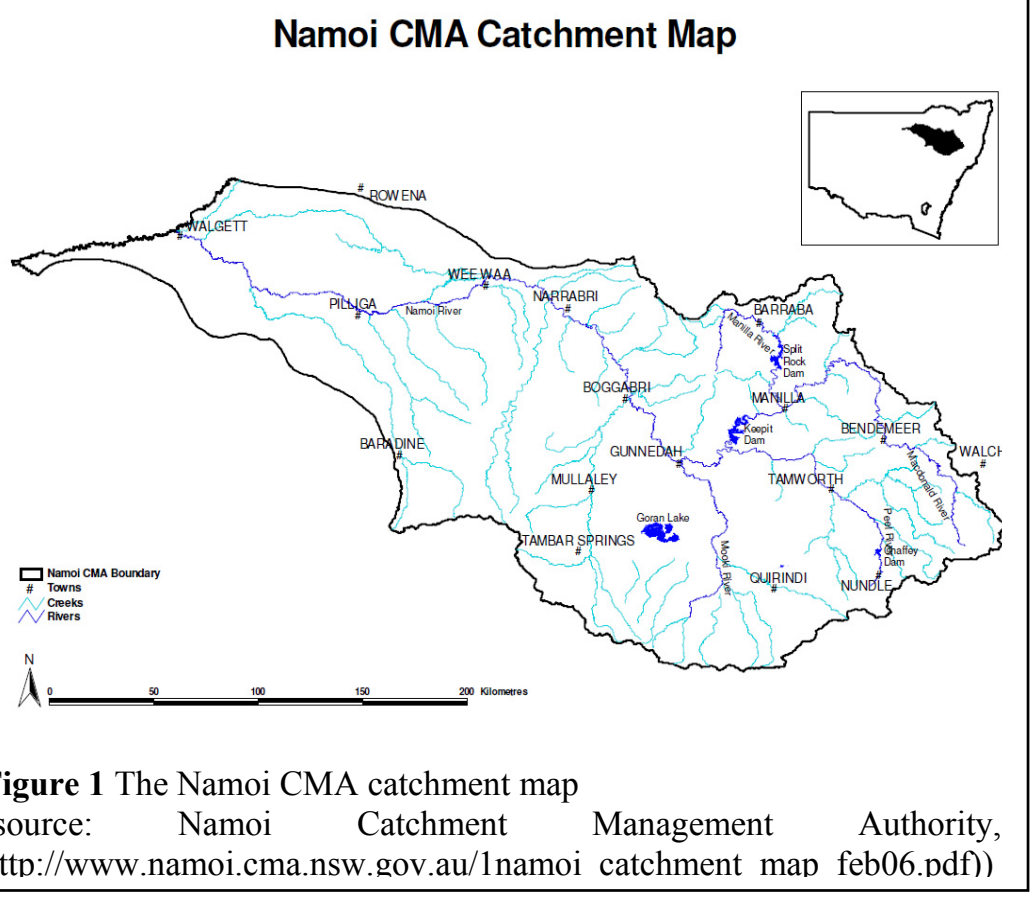
adopt changing crop types and rotation frequency, and least likely to buy water on the temporary or permanent markets. This is most likely to be a reflection of the variability in the financial cost, simplicity and perceived level of risk in adopting these practices. A key influence in the level of uptake of the various management practices was the type of license holder, whereby those who were More Committed to the Farming Business (MCFB) were more likely to adopt the management practices discussed here, compared to those who were More Committed to Environmental Sustainability (MCES). However, these characteristics are inherent, rather than easily changed. The real value of this research is in suggesting more effective ways to engage these license holders, which included through their industry groups (e.g. short courses) and by appeals to the importance of long-term community and business viability.

Keywords: Groundwater, Bayesian network, Adoption 
Ticehurst et al., Using Bayesian networks to advise NRM agencies how to influence the adoption of water ...

\section{INTRODUCTION}

There are a large number of factors that influence land managers' decisions. Pannell et al. (2006) identified that adoption of various management practices depends on personal, social, cultural and economic status of the landholder. Some land holders are more amenable to influence by NRM agencies because of their awareness, skills, knowledge and confidence in the proposed practices. Furthermore, increasing knowledge and awareness of new practices, sometimes through local groups, has been found to positively affect adoption (Barr et al., 2000; Curtis and De Lacy, 1996). Other landholders are less likely to change, because of their values, stage of life and strong focus upon their enterprise profitability (Curtis and Race, 2012; Curtis and Mendham, 2011). Also, past experience can generate a lack of trust in government organizations, which can interfere with adoption (Sharp \& Curtis, 2012). Consequently, we can influence some landholders into adoption, but some we just need to be aware of when thinking about the adoptability of practices and how we need to engage a rural community.

Sharp and Curtis (2012) found correlations between the adoption of various management actions undertaken by groundwater license holders, and a variety of property characteristics, personal values, beliefs and attitudes explored in their study in the Namoi catchment, New South Wales. In this paper we map the causal relationships between them in a Bayesian network.

Bayesian networks (Bns) are becoming increasingly popular for integration in natural resource management because, among other reasons, they can more simply represent a system as they do not need to explicitly represent each process (Borsuk et al., 2004). Bns represent a system by a series of variables joined by causal links, which are described using probability distributions (i.e. sum to $100 \%$ ). The probability distribution of a variable at a point in time, is the likelihood of each possible state or class occurring under that scenario. There are many references which provide more details about Bns including a water resource modelling and management special issue journal introduced by Castelletti and Soncini-Sessa (2007). Bns are particularly useful in water planning and management because their development process is easy to understand and well suited to facilitate stakeholder participation and communication. A more complete list of the advantages and disadvantages of Bns in natural resource management are given in Ticehurst et al. (2009).

This paper provides a brief description of how a Bn was developed to explore influences on the adoption of selected water use efficient management practices in the Namoi catchment, Australia. More detail on the Bn data and development are given in Ticehurst et al. (2013). The working Bn model was used to further explore the research questions proposed by the associated social research team, given below:

- What innovative practices are landholders adopting now and who plans to do so in the future?

- What are the key drivers influencing landholder adoption of innovative practices and/or changes in land use in the Namoi catchment?

This $\mathrm{Bn}$ is a component of a larger integrated model, developed to explore the social, economic, hydrological and ecological trade-offs in the Namoi catchment under various climate and policy scenarios (Jakeman et al., 2012). There have been previous published socio-economic studies in the Namoi catchment (e.g. Kuehne and Bjornlund, 2006; Stenekes et al., 2008), but in future publications we will be linking the social, hydrological, economic and ecological information to provide a more integrated understanding of the impact of water policy and climate change upon landholders.

\section{STUDY AREA AND METHODS}

The Namoi catchment is a profitable irrigated and dryland cotton cropping district in New South Wales (Figure 1). More detail about the Namoi catchment is given in Ticehurst et al. (2013). In 2011, the Namoi catchment produced 728,000 bales of cotton, worth hundreds of millions of dollars (Namoi Cotton, 2012). In the past 20 years, there have been many revisions to water regulations at Federal and State government levels to address the over allocation of surface and groundwater resources for agriculture, and restore a sustainable balance in the division between the social, economic and environmental demands for the water resources.

A $\mathrm{Bn}$ was developed to explore which factors have the most influence over the adoption of water management practices in the past (i.e. past 5 years) and in the future (next 5 years), with particular interest in the effects of climate change and water allocation policy. The model framework was developed in consultation with the social research team, who collected and analysed social survey data in the Namoi catchment in 2010-2011. The method used here to develop the Bn is similar to that of Ticehurst et al. (2011). That being, with a shortlist of management practices of interest (Table 1) undertaken in response to change in climate and water entitlements, an influence diagram was developed using the correlating variables identified 
Ticehurst et al., Using Bayesian networks to advise NRM agencies how to influence the adoption of water ...

from statistical analysis (Sharp and Curtis, 2012). It was reviewed and refined with the social research team and project steering committee to produce the existing model (Figure 2).

Table 1: Management Practices included in the Bayesian network

\begin{tabular}{|l|l|}
\hline Abbreviation & Description of Management Practice (MP) \\
\hline Spray irrigation & Change to spray irrigation \\
\hline SMM & Implement soil moisture mapping and modify flood irrigation approach \\
\hline Deepen dams & Deepen dams and measure dam evaporation losses \\
\hline Buy water & Buy water on the temporary or permanent water markets \\
\hline Change cropping & Change cropping type in rotation and/or crop rotation frequency \\
\hline
\end{tabular}

Ticehurst et al. (2013) details the survey question(s) and any assumptions and expert opinion that was used to populate the Bn. Given that effectively all of the information used to populate each variable was based upon data specific to the study area, model calibration was not necessary. However, it is important to note that the classification of the license holder type came as a result of the social survey analysis by Sharp and Curtis (2012). This analysis identified two types of license holders, those who were More Committed to the Farming Business (MCFB) and those who were More Committed to Environmental Sustainability (MCES). Those MCFB work longer hours on property, do not seek off-property work, have larger properties, larger cultivated and irrigated areas, and larger dam capacities. In contrast those MCES were more likely than the $M C F B$ to trust the NSW Office of Water and in the science used in the Murray Darling Basin Plan, have proconservation and altruistic values and beliefs, believe in human-induced climate change, rate its nature of impact as negative and were less optimistic about their capacity to adapt to climate change impacts. Consequently there was not any survey data collected to directly distinguish between the license holder types, so it was done through expert elicitation. Model evaluation was done qualitatively from review by the social researchers and local stakeholders in the project steering committee. The Bn can be used to show the current level of adoption of each of the management practices by selecting the current states for the input variables (i.e. Compliance scenario, Water entitlement policy and Climate scenario) and then reading the resultant probability distributions for the management practices (e.g. Figure 2). A sensitivity analysis was conducted for each of the management practices of interest using the included function within the Netica software (www.norsys.com). This analysis systematically sets each state in each variable within the network to $100 \%$ probability and then records the impact upon the end variable of interest (ie. Management practice). This way, the variables within the $\mathrm{Bn}$ that had the most influence over that management practice are identified.

A 'hierarchical' sensitivity analysis is where the sensitivity analysis of the management practice identifies which variable is directly linked to it and has the most influence over it. Then a sensitivity analysis is conducted upon that most influential variable, testing only its inputs for the greatest influence. This is repeated throughout the $\mathrm{Bn}$ until there are no longer input variables into the most influential one. The result is a causal link of variables throughout the Bn that show a chain of strongest influence.

\section{RESULTS AND DISCUSSION}

Figure 2 is the final $\mathrm{Bn}$ structure. The scenario selected in this figure is the 'current' condition, so the probabilities shown for the management practices (in blue) are the percentage of people who have adopted each. It shows that Changing crop was the most popular management practice (i.e. $71.1 \%$ of people had undertaken this practice). In comparison, only $16.8 \%$ of people had bought water. There was a moderate adoption of Deepening dams (33.5\%), SMM (39.7\%) and Spray irrigation (31.2\%). One key influence over the level of adoption of the different management practices is likely to be the cost involved in their implementation, and also the perceived simplicity and knowledge required implementing them. This is consistent with the work of others such as Barr et al. (2000).

The sensitivity analysis found that the two most influencing factors for the adoption of Changing crop, SMM, Deepening dams and Buying water were the same, being the license holder type and the trustworthiness of the NSW Office of Water (NoW Trustworthiness) (Table 2). Figure 3 shows the proportion of people who adopted ("Yes"), did not adopt ("No") and who thought the practice was not applicable to them ("N/A") for each management practice, depending on whether they were classed as MCFB or MCES. Those license holders classed as MCFB were 10\%, 7.5\%, 7.3\% and 15\% more likely to adopt SMM, Deepen dams, Buy water, and change cropping, respectively, compared to those MCES (Figure 3). This could be because those who primarily have economic concerns about their farming business are more likely to pursue innovative management practices to ensure they remain economically profitable, and invest time and money into investigating and then implementing those changes. 
Ticehurst et al., Using Bayesian networks to advise NRM agencies how to influence the adoption of water ...

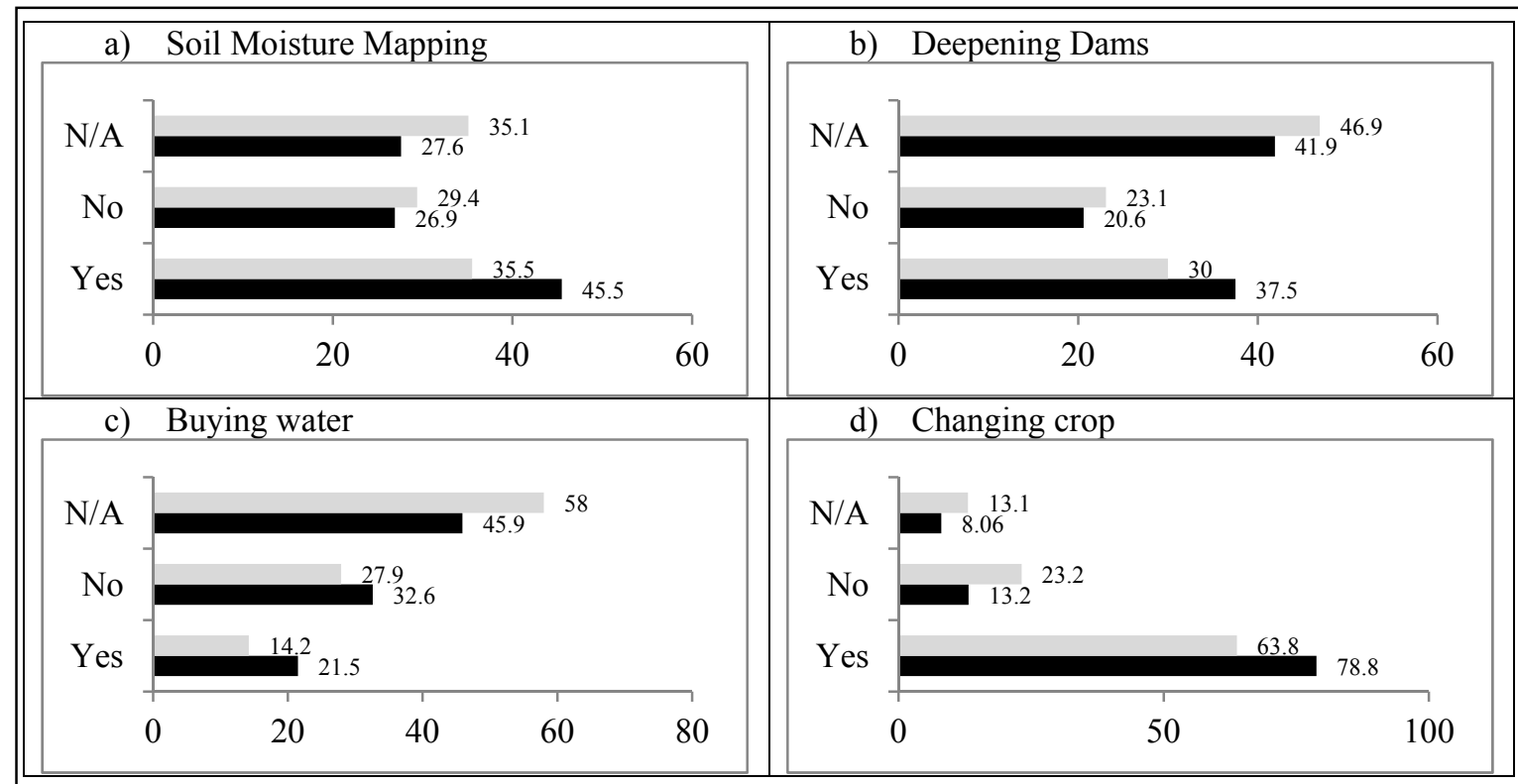

Figure 3: The level of adoption of a) Soil moisture mapping, b) Deepening dams, c) Buying water, and d) Changing crop given the license holder type (More Committed to Farming Business (MCFB) (Black) or More Committed to Environmental Sustainability (MCES) (Gray)) N/A = Believed management practice was not applicable, Yes $=$ Adopted, No $=$ Not adopted

Table 2: The three most influential variables for each management practice.

\begin{tabular}{|l|l|l|l|}
\hline Management practices & \multicolumn{1}{|c|}{$\mathbf{1}^{\text {st }}$ influential } & \multicolumn{1}{|c|}{$\mathbf{2}^{\text {nd }}$ influential } & \multicolumn{1}{|c|}{$\mathbf{3}^{\text {rd }}$ influential } \\
\hline Change cropping & License holder type & NoW Trustworthiness & Did a Short course \\
\hline SMM & License holder type & NoW Trustworthiness & Did a Short course \\
\hline Deepen dam & License holder type & NoW Trustworthiness & Industry group \\
\hline Buy water & License holder type & NoW Trustworthiness & Did a Short course \\
\hline Spray irrigate & Did a Short course & Industry group member & License holder type \\
\hline
\end{tabular}

Similarly, Figure 4 shows the proportion of people who adopted ("Yes"), did not adopt ("No") and who thought the practice was not applicable to them ("N/A") for each of these management practices, depending on whether they were classed as MCFB or MCES. Those who have low trustworthiness in the NoW organization and NoW individual staff were $9.1 \%$ more likely to adopt $S M M, 6.8 \%$ more likely to Deepen dams, $6.6 \%$ more likely to buy water, and $13.5 \%$ more likely to change cropping, compared to those with high trustworthiness. Other research (e.g. Curtis and Race, 2012) suggest that a lack of trust decreases adoption. The result here is probably because the vast majority of people $(90 \%)$ with low trust in NoW were $\mathrm{MCFB}$, so trust is acting as a surrogate for license holder type.

The most influential variable for the uptake of spray irrigation, and the third for SMM, Change cropping and buying water was the completion of a short course (Table 2). Those who had completed a short course were $7.5 \%, 7.3 \%$ and $4.6 \%$ more likely to adopt spray irrigation, SMM, and buy water, respectively, compared to those who had not completed the course (results not shown). This could indicate that those who completed short courses were more aware and knowledgeable about the management practice options available to them and therefore, more likely to take up those practices. Barr et al. (2000) also found the positive influence of knowledge and awareness over adoption.

The second most influential variable for spray irrigation, and third for deepening dams was being a member of an industry group. Those who were an industry group member were $2.8 \%$ more likely to spray irrigate, but only $0.3 \%$ more likely to Deepen dams (results not shown). This is a small impact here and may just be noise, but other research has found similar results (e.g. Curtis and De Lacy, 1996).

The hierarchical sensitivity analysis results were the same for Change cropping, SMM, Deepen dams and Buy water. The influential chain from the analysis was license holder type, property scale, cultivated area and groundwater zone. This confirms the results already suggested, that the adoption of these management practices are strongly based upon the type of person managing the land, their scale of operation, the farming enterprise and its focus, which is largely influenced by where in the Namoi catchment their property is (i.e. their groundwater zone). These characteristics are fundamentally set and quite difficult to influence in terms of encouraging the adoption of different management practices. 
Ticehurst et al., Using Bayesian networks to advise NRM agencies how to influence the adoption of water ...

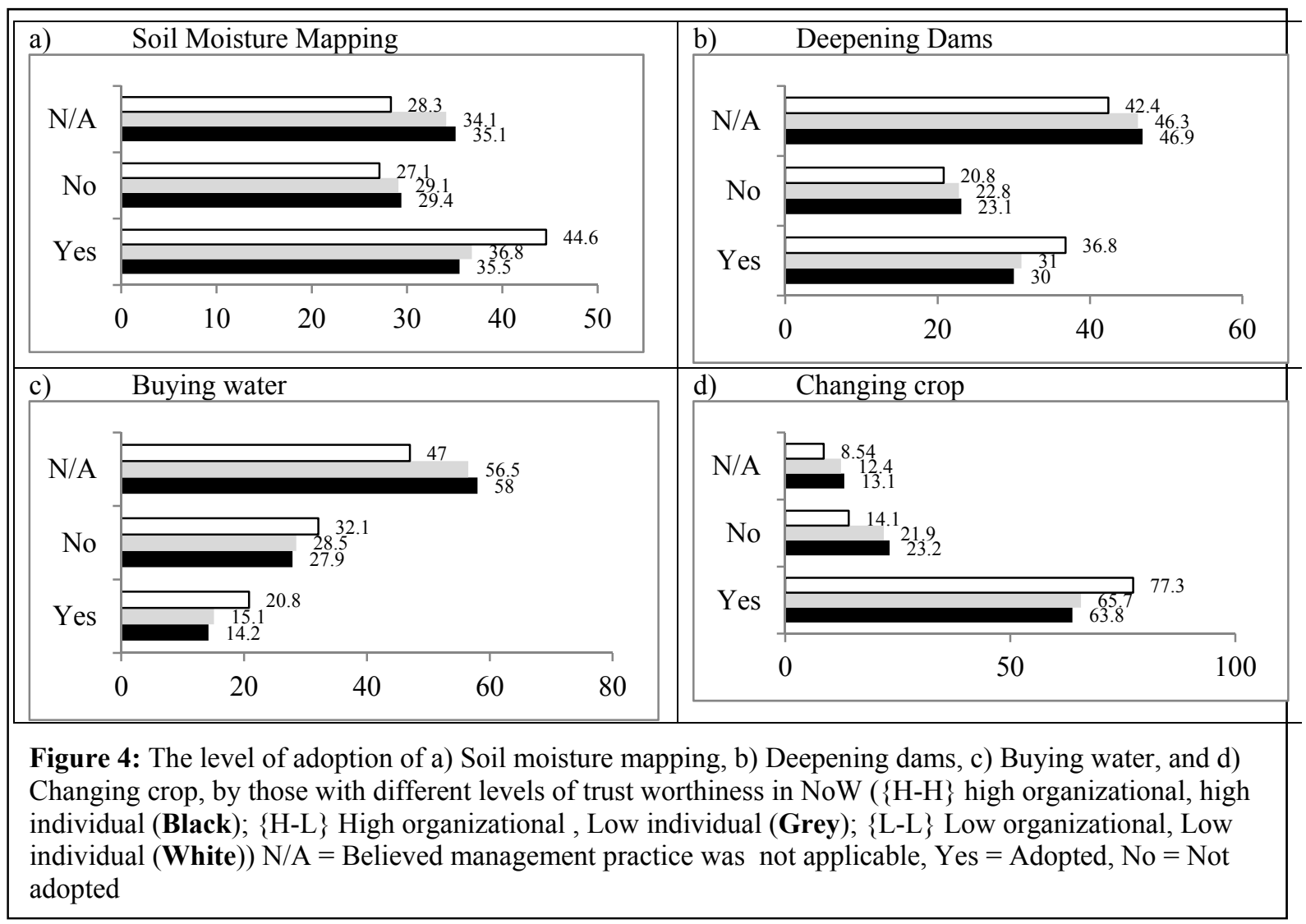

Climate did not have a significant impact upon the adoption of these management practices. This could have been because of the lack of concern about the climate, as found in other analysis Sharp and Curtis (2012), because current predictions for this area suggest that rainfall may actually increase with the changing climate.

\section{DISCUSSION AND CONCLUSIONS}

This paper describes the development of a Bayesian network (Bn) model to investigate what influences the adoption of various management practices that might be undertaken with reduced water availability. Of the management practices included in the $\mathrm{Bn}$, license holders were most likely to Change cropping $(71.1 \%$ adopted), and least likely to Buy water (16.8\%). There was a moderate adoption of carrying out Soil Moisture Mapping (39.7\%), Deepening dams (33.5\%) and Spray irrigation (31.2\%). The difference in could be a reflection of the variability in financial cost, simplicity and perceived level of risk in adopting these practices (i.e. cheap, simple and low risk actions will be adopted before more expensive, difficult and risky ones).

The license holder type, being either More Committed to the Farming Business (MCFB) or More Committed to Environmental Sustainability (MCES), was a key influence in the level of uptake of the various management practices. Compared to MCES, those who were MCFB were more likely to adopt all of the management practices in the model, but this was particularly true for Changing crop, SMM, Deepening dams, and Buying water. However, further analysis of the license holder type is recommended, given its reliance upon expert opinion in the model. Increasing license holders' awareness and knowledge of various practices by providing them with social networks (membership of industry groups) and support through short courses was also a key influence in the adoption of these practices.

NRM practitioners intending to influence the behaviour of rural landholders should focus on interventions that are expected to address the underlying barriers to adoption. To the extent that those barriers are readily addressed, such as by raising awareness, improving knowledge or management skills, or providing funds to offset the costs of implementation, then efforts should be made to effect those changes. In this study, it seems that efforts to improve the adoption of more water efficient practices should include encouraging membership of industry groups and participation in short courses. It seems that the license holder type (MCFB or MCES) was an important influence on adoption of more water efficient practices, but it is difficult to change the underlying values, beliefs and attitudes. However, these types provide useful information about how those landholders might be more effectively engaged by NRM agencies. For example, efforts to engage those with a stronger business focus should emphasise the benefits of new approaches for the farm business and the long-term viability of the local rural community. 
Ticehurst et al., Using Bayesian networks to advise NRM agencies how to influence the adoption of water ...

\section{ACKNOWLEDGEMENTS}

This work was funded by the National Centre for Groundwater Research and Training, and the Australian Cotton Co-operative Research Centre. Special thanks to Dr Emily Sharp, who conducted the social survey which this research is based upon.

\section{REFERENCES}

Barr, N., Ridges, S., Anderson, N., Gray, I., Crockett, J., Watson, B., Hall, N.,( 2000). Adjusting for Catchment Management: Structural Adjustment and Its Implications for Catchment Management in the Murray Darling Basin. Available from:. Murray-Darling Basin Commission, Canberra, ACT http://publication.mdbc.gov.au/product_info.php?products_id $1 / 4228$.

Borsuk ME, Stow CA and Reckhow KH (2004), A Bayesian network of eutrophication models for synthesis prediction, and uncertainty analysis. Ecological Modelling. 173, 219-239.

Castelletti A and Soncini-Sessa R (2007), Bayesian networks in water resource modelling and management, Environmental Modelling and Software, 22(8), 1073-1074Curtis, A., De Lacy, T., 1996. Landcare in Australia: does it make a difference? Journal of Environmental Management 46, 119e137.

Curtis, A., and De Lacy, T., (1996). Landcare in Australia: does it make a difference? Journal of Environmental Management; 46, 119-137.

Curtis A and Mendham, M. (2011), Bridging the gap between policy and management of natural resources. In D. Pannell \& F, Vanclay (Eds.), Changing land management: adoption of new practices by rural landholders. Pp 377-397. CSIRO Publishing, Melbourne, Australia

Curtis, A. and Race, D. (2012), Management of riparian zones by rural landholders, Chapter 6 in E. Lefroy, A. Curtis, A. Jakeman and J. McKee (eds) Landscape Logic: Integrated science for landscape management, CSIRO publishing, Collingwood, Melbourne.

Jakeman' A., Kelly R, Ticehurst J, Blakers' R, Croke’ B, Curtis' A, Fu’ B, Gardner’ A, Guillaume J, Hartley’ M, Holley' C, Hutchings' P, Pannell' D, Powell' S, Ross' A, Sharp' E, Sinclair' D, Wilson' A, (2012), Modelling for the complex issue of groundwater management, SIMULTECH conference, Rome, Italy, $28^{\text {th }}-31$ st July.

Kuehne G and H Bjornlund (2006), Frustration, confusion and uncertainty - Qualitative responses from Namoi Valley Irrigators, Journal of the Australian Water Association, 51-55.

Namoi Cotton (2012), Annual Report, Namoi Cotton, http://www.namoicotton.com.au/pdf/2012/AnnualReport2012.pdf

Pannell DJ, Marshall GR, Barr N, Curtis A, Vanclay F and Wilkinson R (2006), Understanding and promoting adoption of conservation technologies by rural landholders. Australian Journal of Experimental Agriculture 46(11): 1407-1424.

Sharp E and Curtis A (2012), Groundwater management in the Namoi: a social perspective, Institute for Land, Water and Society, Charles Sturt University, Albury, NSW, 2640.

Stenekes N, Russell J, Tucker C and Mooney C (2008), Water for what? Productive and environmental values for water: Understanding social values, Australian Government Bureau of Rural Sciences, Canberra, August 2008.

Ticehurst J.L, Curtis A and Merritt W.S (2009), Can Bayesian networks compliment traditional analysis of social data? A case study on the adoption of current recommended practices (CRP) in the Wimmera region, Landscape Logic Technical report No. 13, http://www.landscapelogicproducts.org.au

Ticehurst J.L, Curtis A and Merritt W.S (2011), Using Bayesian Networks to complement conventional analyses to explore landholder management of native vegetation, Environmental Modelling and Software, 26:52-65.

Ticehurst J.L, Sharp E and Curtis A (2013), A Bayesian Network to Explore the Adoption of Various Management Practices for use in an Integrated Model of Water Access by Groundwater License Holders', Final Technical Report, National Centre for Groundwater Research and Training, Adelaide, SA 